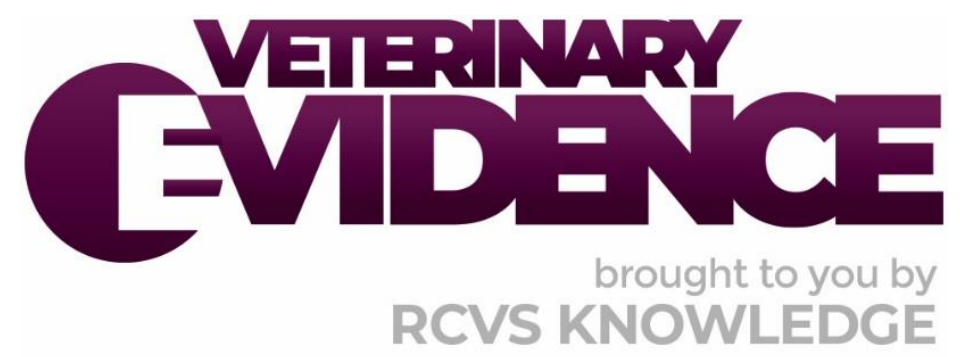

\title{
Can sedation be used for equine lameness investigation?
}

\section{A Knowledge Summary by}

Helene Termansen DVM PGDip VCP (Equine) MRCVS ${ }^{1^{*}}$

Lucinda Meehan BVSc MSc Cert AVP (VDI) DipECVDI MRCVS ${ }^{2}$

\footnotetext{
${ }^{1}$ Langford Vets, University of Bristol, Langford, BS40 5DU

2 St John's Innovation Centre, Cowley Rd, Cambridge, CB4 OWS

*Corresponding Author (termansen94@gmail.com)
}

ISSN: 2396-9776

Published: 18 Jun 2021

in: The Veterinary Evidence journal Vol 6, Issue 2

DOI: https://doi.org/10.18849/ve.v6i2.373

Reviewed by: Michael De Cozar (BSc (Hons) BVetMed MRCVS) and Josh Slater (PhD Dip ECEIM)

Next Review Date: 19 Jun 2022 


\section{KNOWLEDGE SUMMARY}

\section{PICO question}

In horses undergoing lameness investigation, does sedation with $\alpha_{2}$-adrenergic agonists alone versus sedation with $\alpha_{2}$-adrenergic agonists in combination with butorphanol tartrate effect the degree of lameness?

\section{Clinical bottom line}

\section{Category of research question}

\section{Diagnosis}

\section{The number and type of study designs reviewed}

Six papers were critically reviewed. There were three crossover clinical studies, two crossover controlled clinical studies and a randomised controlled clinical study

\section{Strength of evidence}

\section{Moderate}

\section{Outcomes reported}

There was limited evidence to suggest that xylazine and romifidine in combination with butorphanol has an effect on forelimb lameness and that detomidine has an effect on hindlimb lameness.

Most evidence suggests that xylazine alone or in combination with butorphanol has no effect on the lameness

\section{Conclusion}

In general, sedating a horse with an $\alpha_{2}$-adrenergic agonist alone or in combination with butorphanol tartrate does not change the baseline degree of lameness. Due to the large variation in the measurements, the small magnitude of few significant effects and the inconsistency of these significant findings, there is insufficient evidence to recommend avoiding the use of sedation in cases where it would increase the safety of those involved. However, regardless of protocol used, clinicians must appreciate the possibility of individual horse variation

\section{How to apply this evidence in practice}

The application of evidence into practice should take into account multiple factors, not limited to: individual clinical expertise, patient's circumstances and owners' values, country, location or clinic where you work, the individual case in front of you, the availability of therapies and resources.

Knowledge Summaries are a resource to help reinforce or inform decision making. They do not override the responsibility or judgement of the practitioner to do what is best for the animal in their care. 


\section{Clinical Scenario}

When physical restraint is not sufficient to ensure safe and correct injection of diagnostic analgesia, sedation may be required. Many veterinary clinicians remain concerned about the effect sedation could have on the locomotory pattern and degree of lameness. Is there evidence to suggest cause for concern and which sedation protocol should one choose if needed?

\section{The evidence}

Six papers have been published on the use of $\alpha_{2}$-agonists for lameness investigation. Most of the studies were controlled clinical trials, however two were crossover trials only. The level of evidence of these papers was therefore moderate.

\section{Summary of the evidence}

\begin{tabular}{|c|c|}
\hline \multicolumn{2}{|l|}{ Morgan et al. (2020) } \\
\hline Population: & $\begin{array}{l}\text { Six adult horses with a lameness of grade } 1 / 5 \text { or less on a subjective } \\
\text { lameness scale previously described by Ross (2011) (AAEP lameness } \\
\text { scale): } \\
\text { - Three mares, three geldings } \\
\text { - Three Thoroughbreds, three Standardbreds }\end{array}$ \\
\hline Sample size: & Six horses \\
\hline Intervention details: & $\begin{array}{l}\text { - } \mathrm{N}=6 \text { Grade } 3-4 / 5 \text { AAEP lameness grade unilateral forelimb } \\
\text { lameness induced with set screws inserted into a custom- } \\
\text { made shoe. } \\
\text { - Each horse received six treatments with a minimum } \\
\text { washout of } 7 \text { days between trials: xylazine hydrochloride at } \\
0.1 \text { or } 0.2 \mathrm{mg} / \mathrm{kg} \mathrm{IV} \text {, acepromazine maleate at } 0.02 \text { or } 0.04 \\
\mathrm{mg} / \mathrm{kg} \mathrm{IV}, 1 \mathrm{ml} \text { saline IV, local analgesia (abaxial nerve block } \\
-4 \mathrm{ml} 2 \% \text { mepivacaine hydrochloride) } \\
10 \mathrm{ml} \text { blood was collected by direct venipuncture for } \\
\text { quantification of xylazine, acepromazine and mepivacaine at } \\
\text { each time point. }\end{array}$ \\
\hline Study design: & Randomised placebo controlled crossover trial \\
\hline Outcome studied: & $\begin{array}{l}\text { - Lameness was assessed subjectively using digital video } \\
\text { recordings and objectively by using an objective lameness } \\
\text { assessment system - difference in minimum head position } \\
\left(H D_{\text {min }}\right) \text {, difference in maximum head position }\left(H D_{\text {max }}\right) \text {, head } \\
\text { movement asymmetry }(V S) \text { and stride rate were measured. } \\
\text { - Each assessment was categorised as sedated, somewhat } \\
\text { sedated or not sedated and ataxic, equivocally ataxic or not } \\
\text { ataxic. } \\
\text { - The horses were assessed at time } 0 \text { (immediately after } \\
\text { lameness induction) and } 10,30,45 \text { and } 60 \text { minutes post- } \\
\text { treatment. } \\
\text { Intra and interobserver agreement of subjective lameness } \\
\text { grade. }\end{array}$ \\
\hline $\begin{array}{l}\text { Main findings: } \\
\text { (relevant to PICO question): }\end{array}$ & $\begin{array}{l}\text { - Acepromazine }(0.02 \text { and } 0.04 \mathrm{mg} / \mathrm{kg}) \text { and xylazine }(0.2 \\
\mathrm{mg} / \mathrm{kg}) \text { did not result in significant differences in objective } \\
\text { lameness parameters at any time point. }\end{array}$ \\
\hline
\end{tabular}




\begin{tabular}{|l|l|}
\hline - & Xylazine $(0.1 \mathrm{mg} / \mathrm{kg}$ ) did not result in significant differences \\
in $\mathrm{HD}_{\min }$ or VS. \\
-
\end{tabular}

Beck Júnior et al. (2019)

\begin{tabular}{|c|c|}
\hline Population: & $\begin{array}{l}\text { Adult horses categorised as free of lameness by using objective } \\
\text { lameness measurement: } \\
\text { - Four geldings, } 12 \text { mares } \\
\text { - Four Brazilian Warmblood horses and } 12 \text { crossbreeds }\end{array}$ \\
\hline Sample size: & 16 horses \\
\hline Intervention details: & $\begin{array}{l}\text { - Metal clamps were placed on the hoof wall of either the } \\
\text { right or the left hindlimb (random selection) and tightened } \\
\text { until horses showed a 3-4/5 AAEP lameness grade. } \\
\text { - Each horse received three treatments: } \\
\text { 1. xylazine hydrochloride } 10 \%(0.3 \mathrm{mg} / \mathrm{kg}) \\
\text { 2. xylazine hydrochloride } 10 \%(0.3 \mathrm{mg} / \mathrm{kg}) \text { combined } \\
\text { with butorphanol tartrate }(0.01 \mathrm{mg} / \mathrm{kg}) \\
\text { 3. untreated control group } \\
\text { Between each treatment there was a washout period of at } \\
\text { least } 48 \mathrm{hrs} \text {. }\end{array}$ \\
\hline Study design: & Controlled crossover trial \\
\hline Outcome studied: & $\begin{array}{l}\text { - Lameness was evaluated using an objective lameness } \\
\text { assessment system (pelvic vertical movement asymmetry) } \\
\text { before sedation (time } 0 \text { ), and at 20,30, and } 40 \text { minutes post } \\
\text { sedation. }\end{array}$ \\
\hline
\end{tabular}




\begin{tabular}{|c|c|}
\hline & $\begin{array}{l}\text { - Level of sedation was evaluated at the same times using a } \\
\text { physical and behavioural scale (0-3) and by measuring the } \\
\text { head height above ground. }\end{array}$ \\
\hline $\begin{array}{l}\text { Main findings: } \\
\text { (relevant to PICO question): }\end{array}$ & $\begin{array}{l}\text { - There was no difference in pelvic asymmetry between } \\
\text { xylazine, xylazine with butorphanol and untreated control } \\
\text { group at the different evaluation times. } \\
\text { - There was no correlation between head height above } \\
\text { ground and lameness improvement. }\end{array}$ \\
\hline Limitations: & $\begin{array}{l}\text { - The sample size was small. } \\
\text { - Only hindlimb lameness was studied. } \\
\text { - Trotting speed and stride rate were not measured. } \\
\text { - The veterinarian evaluating the level of sedation was aware } \\
\text { of which group the horse was in, allowing potential for bias. } \\
\text { - } 3-4 / 5 \text { AAEP lameness grade is a substantial lameness and } \\
\text { questions whether the results are repeatable for more } \\
\text { subtle lameness. }\end{array}$ \\
\hline
\end{tabular}

\section{Moorman et al. (2019)}

\begin{tabular}{|c|c|}
\hline Population: & $\begin{array}{l}\text { Adult polo horses with naturally occurring forelimb and/or hindlimb } \\
\text { lameness varying from grade 1-3 on the AAEP lameness grading } \\
\text { system: } \\
\text { - } 13 \text { mares, four geldings } \\
\text { - } 10 \text { Thoroughbreds, one Thoroughbred cross, two Argentine } \\
\text { Thoroughbreds, one Argentine polo pony, one Crillo, one } \\
\text { Standardbreed cross and one American Quarter Horse }\end{array}$ \\
\hline Sample size: & 17 horses \\
\hline Intervention details: & $\begin{array}{l}\text { Seven protocols were trialed with a washout period of at least } 7 \\
\text { days between each. The protocols were: } \\
\text { - } \text { saline }(0.09 \% \mathrm{NaCl}, 2 \mathrm{ml} \mathrm{IV}) \\
\text { - } \text { xylazine hydrochloride }(0.33 \mathrm{mg} / \mathrm{kg} \mathrm{IV}) \\
\text { - } \text { detomidine hydrochloride }(0.007 \mathrm{mg} / \mathrm{kg} \mathrm{IV}) \\
\text { - } \text { romifidine hydrochloride }(0.033 \mathrm{mg} / \mathrm{kg} \mathrm{IV}) \\
\text { xylazine hydrochloride }(0.33 \mathrm{mg} / \mathrm{kg} \mathrm{IV}) \text { and butorphanol } \\
\text { - } \text { tartrate }(0.007 \mathrm{mg} / \mathrm{kg} \mathrm{IV)} \\
\text { detomidine hydrochloride }(0.007 \mathrm{mg} / \mathrm{kg} \mathrm{IV}) \text { and butorphanol } \\
\text { - } \text { romifidine hydrochloride }(0.033 \mathrm{mg} / \mathrm{kg} \mathrm{IV}) \text { and butorphanol } \\
\text { tartrate }(0.007 \mathrm{mg} / \mathrm{kg} \mathrm{IV}) .\end{array}$ \\
\hline Study design: & Placebo controlled crossover trial \\
\hline Outcome studied: & $\begin{array}{l}\text { Degree of sedation (subjective) } 1-5,1 \text { being mild sedation } \\
\text { and } 5 \text { being deep sedation. } \\
\text { - Degree of sedation (objective): Head-height to horse-height } \\
\text { ratio. } \\
\text { - Mechanical nociceptive threshold (MNT): pressure applied } 1 \\
\mathrm{~cm} \text { proximal to the coronary band at a rate of approximately } \\
5-10 \mathrm{~kg} / \mathrm{cm}^{2} / \mathrm{s} \text { until the horse displayed avoidance } \\
\text { behaviour. }\end{array}$ \\
\hline
\end{tabular}




\begin{tabular}{|c|c|}
\hline & $\begin{array}{l}\text { - Subjective (modified AAEP lameness scale) and objective } \\
\text { lameness assessment. } \\
\text { - All outcomes were assessed prior to (time } 0 \text { ) and 10, 15, 20, } \\
\text { 30, and } 40 \text { minutes post administration of each protocol. }\end{array}$ \\
\hline $\begin{array}{r}\text { Main findings: } \\
\text { (relevant to PICO question): }\end{array}$ & $\begin{array}{l}\text { - Across all data points, there was a significant difference in } \\
\text { head movement asymmetry (VSFL) from baseline for } \\
\text { xylazine alone and the romifidine-butorphanol combination. } \\
\text { When looking at pelvic movement asymmetry (VSHL), there } \\
\text { was a significant difference from baseline for detomidine } \\
\text { hydrochloride alone across all data points. } \\
\text { - None of the measurements recorded after injection of any } \\
\text { of the drugs were significantly different from the } \\
\text { corresponding measurements recorded after injection of } \\
\text { saline. } \\
\text { - Apart from xylazine alone, MNT measurements were } \\
\text { significantly higher than baseline and corresponding saline } \\
\text { measurements for all time points. } \\
\text { Large interindividual variation in measurements recorded } \\
\text { regardless of sedation and time postadministration. }\end{array}$ \\
\hline Limitations: & $\begin{array}{l}\text { - The initial lameness evaluation was performed } 1 \text { month } \\
\text { prior to the study. The lameness degree could have changed } \\
\text { in this time, regardless of sedation protocol. Lameness may } \\
\text { also have changed during the washout periods (naturally } \\
\text { occurring lameness). } \\
\text { - Small sample size. }\end{array}$ \\
\hline
\end{tabular}

Rettig et al. (2016)

\begin{tabular}{|c|c|}
\hline Population: & $\begin{array}{l}44 \text { horses of which four horses were sound and } 40 \text { were lame on a } \\
\text { forelimb or hindlimb or both. }\end{array}$ \\
\hline Sample size: & 44 horses \\
\hline Intervention details: & $\begin{array}{l}\text { The horses were divided into subgroups of sound, mildly } \\
\text { lame and markedly lame and were then randomly split into } \\
\text { treatment and control groups of approximately equal } \\
\text { numbers. } \\
\text { - Treatment group was treated with xylazine }(0.3 \mathrm{mg} / \mathrm{kg} \\
\text { diluted with saline to } 10 \mathrm{ml} \text { total IV) and the control group } \\
\text { was treated with sterile saline ( } 10 \mathrm{ml} \text { IV). }\end{array}$ \\
\hline Study design: & Randomised, placebo controlled \\
\hline Outcome studied: & $\begin{array}{l}\text { - Objective lameness evaluation (head/pelvic movement } \\
\text { asymmetry) was carried out using an objective lameness } \\
\text { assessment system prior to (time } 0 \text { ) and } 20 \text {, and } 60 \text { minutes } \\
\text { post-treatment. The number of horses staying the same, } \\
\text { improving and worsening in head or pelvic movement } \\
\text { asymmetry were compared between the treatment and } \\
\text { control group at each time point ( } 0 \text { vs. } 20 \text { and } 0 \text { vs. } 60 \text { ) } \\
\text { - Head height above ground was used as an objective } \\
\text { evaluation of degree of sedation and the horses were also } \\
\text { evaluated subjectively for ataxia. }\end{array}$ \\
\hline
\end{tabular}




\begin{tabular}{|c|c|c|}
\hline \multicolumn{1}{|c|}{ Main findings: } & - & Stride rate was measured. \\
\hline (relevant to PICO question): & The study found no statistically significant differences in \\
& head or pelvic movement asymmetry between the two \\
groups. This suggests that the dose of xylazine used in this \\
study does not mask lameness. \\
-
\end{tabular}

Da Silva Azevedo et al. (2015)

\begin{tabular}{|c|c|}
\hline Population: & $\begin{array}{l}\text { Adult horses that had an AAEP lameness grade of 1-3 on any limb - } \\
16 \text { crossbreeds }\end{array}$ \\
\hline Sample size: & 16 horses \\
\hline Intervention details: & $\begin{array}{l}\text { - All horses were evaluated for head and pelvic movement } \\
\text { asymmetry using the lameness locator before treatment. } \\
\text { Eight horses were then treated with acepromazine } 1 \% \\
(0.025 \mathrm{mg} / \mathrm{kg} \mathrm{IV}) \text { and the other eight were treated with } \\
\text { xylazine } 10 \%(0.25 \mathrm{mg} / \mathrm{kg} \mathrm{IV}) \text {. The horses were then re- } \\
\text { evaluated } 5 \text { minutes later using the lameness locator. On the } \\
\text { second day of the study the horses initially treated with } \\
\text { acepromazine were treated with xylazine and vice versa. The } \\
\text { same data collection protocol was used on day } 2 \text {. }\end{array}$ \\
\hline Study design: & Crossover trial \\
\hline Outcome studied: & $\begin{array}{l}\text { Five minutes after treatment, lameness was reevaluated } \\
\text { using the lameness locator } \\
\text { - The same data collection protocol was used on day } 2 \text {. }\end{array}$ \\
\hline $\begin{array}{r}\text { Main findings: } \\
\text { (relevant to PICO question): }\end{array}$ & $\begin{array}{l}\text { - There was no difference in fore- and hindlimb asymmetry } \\
\text { before and after treatment with xylazine or acepromazine. } \\
\text { - There was no difference between horses after xylazine or } \\
\text { acepromazine. }\end{array}$ \\
\hline Limitations: & $\begin{array}{l}\text { - No control treatment group to account for changes in } \\
\text { lameness through the course of the study. } \\
\text { - The study also had a small population size. } \\
\text { - The study only looked at the effects up to } 5 \text { minutes }\end{array}$ \\
\hline
\end{tabular}




\begin{tabular}{|l|l|}
\hline & $\begin{array}{l}\text { postsedation and so may have limited relevance to clinical } \\
\text { lameness investigations where horses are evaluated over } \\
\text { longer periods. }\end{array}$ \\
\hline
\end{tabular}

\begin{tabular}{|c|c|}
\hline \multicolumn{2}{|l|}{ Buchner et al. (1999) } \\
\hline Population: & $\begin{array}{l}17 \text { adult horses of which nine were sound and eight had a chronic, } \\
\text { slight (degree } 1-2 / 5 \text { ) forelimb lameness: } \\
\text { - } 10 \text { geldings, three stallions, four mares }\end{array}$ \\
\hline Sample size: & 17 horses \\
\hline Intervention details: & $\begin{array}{l}\text { - On day } 1 \text { all horses were sedated with detomidine }(10 \mu \mathrm{g} / \mathrm{kg} \\
\mathrm{IV}) \text {. } \\
\text { - On day } 2 \text { all horses received the same sedation which was } \\
\text { then antagonised with atipamezole }(100 \mu / \mathrm{kg} \text { IV) after } 15 \\
\text { minutes. }\end{array}$ \\
\hline Study design: & Crossover trial \\
\hline Outcome studied: & $\begin{array}{l}\text { - The locomotion pattern was recorded while trotting at a } \\
\text { constant speed of } 3.9 \mathrm{~m} / \mathrm{s} \text { on a treadmill. } \\
\text { - Level of sedation was evaluated using measurements of } \\
\text { head height above ground and pulse rate. } \\
\text { Objective lameness was evaluated using head acceleration } \\
\text { asymmetry, stride and stance duration and stride length. } \\
\text { Measurements were collected at time } 0 \text { and } 15,25,35,45 \text {, } \\
\text { and } 60 \text { minutes postsedation. On day } 2 \text { the same recording } \\
\text { procedure was performed with antagonisation of the } \\
\text { sedation immediately following the } 15 \text { minute recording. }\end{array}$ \\
\hline $\begin{array}{l}\text { Main findings: } \\
\text { (relevant to PICO question): }\end{array}$ & $\begin{array}{l}\text { - Sedation with detomidine did not change the degree of } \\
\text { lameness in the eight horses with chronic forelimb lameness } \\
\text { but altered the general locomotion pattern (increase stride } \\
\text { length, stride duration and stance duration). } \\
\text { - Some of the increase in stride length and duration could be } \\
\text { reversed using atipamezole. } \\
\text { - Large interindividual variation in measurements recorded } \\
\text { regardless of sedation and time postadministration. }\end{array}$ \\
\hline Limitations: & $\begin{array}{l}\text { - Only looks at forelimb lameness. } \\
\text { - Treadmill used to compare stride variables and the findings } \\
\text { may therefore not be applicable in traditional lameness } \\
\text { evaluations on ground. } \\
\text { - No control group to account for changes in lameness } \\
\text { through the course of the study. }\end{array}$ \\
\hline
\end{tabular}

\section{Appraisal, application and reflection}

Equine lameness is a common reason for seeking veterinary attention (Seitzinger et al., 2000). Intrasynovial or perineural diagnostic analgesia is the most valuable tool for localising pain causing lameness (Bassage \& Ross, 2011). However, these procedures can be difficult to perform on fractious, highly-strung or needle shy horses and therefore pose a significant occupational risk to the clinician and assistants. The use of chemical restraint to increase safety has therefore been researched. Whilst sedation eases patient compliance, some clinicians avoid its use due to the possible analgesic effects of these drugs (Pilsworth \& Dyson, 2015). A recent review 
found evidence to support the use of $\alpha_{2}$-agonists on their own for lameness investigation (De Cozar, 2019). Three clinical papers have since investigated the use of $\alpha_{2}$-agonists in combination with butorphanol (Beck Júnior et al., 2019; Moorman et al., 2019; and Morgan et al., 2020).

Of the $\alpha_{2}$-agonists, xylazine is the most frequently studied. When looking at hindlimb lameness, Da Silva Azevedo et al. (2015) found no significant difference in lameness degree after 5 minutes when using xylazine alone. Rettig et al. (2016), Beck Júnior et al. (2019) and Moorman et al. (2019) found the same tendency up to 60,40 and 40 minutes respectively. Furthermore Beck Júnior et al. (2019) found no significant difference when using xylazine in combination with butorphanol while Moorman et al. (2019) found a significant difference from baseline lameness at $4 / 5$ time points but no difference from administration of saline at any time point. When using the objective measurement of head movement asymmetry, Morgan et al. (2020) found no significant difference from baseline or saline treatment when using xylazine. However, Moorman et al. (2019) found a significant difference across all data points when using xylazine alone in naturally-occurring lameness, and Rettig et al. (2016) found a decrease in some forelimb lameness at 60 minutes but no overall significant effect. It was therefore suggested that caution should be taken when interpreting forelimb lameness following administration of xylazine. Only one paper (Moorman et al. (2019)) assessed the effect of xylazine in combination with butorphanol on head movement asymmetry. They found a significant difference from baseline lameness at 2/5 time points. This result is however based on data from a small sample and Moorman et al. (2019) were unable to show statistical difference between any of the treated groups and the control group. The locomotory pattern after administration of xylazine was assessed in two papers (Morgan et al., 2020; and Rettig et al., 2016). These papers showed an inconsistent reduction of stride rate that was only significant at 45 and 20 minutes respectively. Since the lameness remained unchanged, it is unlikely that these findings are of clinical relevance. There is therefore very little evidence to suggest that the xylazine, with or without the addition of butorphanol should change degree of lameness.

The use of detomidine hydrochloride was studied by Buchner et al. (1999) and Moorman et al. (2019). Buchner et al. (1999) found that the use of detomidine did not alter forelimb lameness degree but did alter the general locomotory pattern. Likewise, the study by Moorman et al. (2019) found no effect of detomidin on head movement asymmetry but did find a significant difference in pelvic movement asymmetry across all data points. They found no significant difference in head or pelvic movement asymmetry when using detomidine combined with butorphanol.

The use of romifidine for lameness evaluations was only studied by Moorman et al. (2019). Their results showed a significant difference in head movement asymmetry when horses had received romifidine in combination with butorphanol but showed no difference in pelvic movement asymmetry. Romifidine used on its own showed an inconsistently significant difference in head and pelvic movement asymmetry from baseline.

Of the papers reviewed, four were controlled clinical trials of which three were crossover trials and two were randomised trials. The remaining two papers were crossover trials without a control group. An attempt has therefore been made to limit bias and the level of evidence was deemed moderate. Nevertheless, caution must be shown due to the small sample sizes used in these papers. Only two of the studies compared objective and subjective lameness evaluation after sedation had been used, which questions whether there would be agreement between the two in a clinical setting. Furthermore, 2/6 of the papers reviewed induced lameness experimentally whilst the remaining four evaluated the effect of sedation on naturally occurring lameness, which could have changed throughout the course of the studies. The degree of lameness assessed spanned from 1-4 on the AAEP lameness scale and thus related well to cases seen in clinical practice. While the experimental design used in the papers reviewed is robust, there is a large variation between observations. This indicates that large sample sizes would be required to detect potential significant effects of different sedation protocols. 
In conclusion, there is limited evidence to suggest that using an $\alpha_{2}$-adrenergic agonist alone or in combination with butorphanol tartrate for lameness evaluation changes the baseline lameness in general. In the reviewed literature, there is large variation of the measurements recorded for different horses, the magnitude of the significant effects of using sedation is small and there is inconsistency in these significant effects both throughout a single study and between studies. There is therefore insufficient evidence to recommend avoiding the use of sedation in cases where it would increase the safety of those involved. The evidence regarding the use of xylazine, the most frequently studied sedative, indicates there is no clinically significant change in lameness. However, regardless of protocol used, clinicians must be aware of the possibility of individual horse variation. Additional studies assessing the effect of $\alpha_{2}$-adrenergic agonists in combination with butorphanol tartrate on lameness degree are needed to ensure a more reliable conclusion. Further investigation into how sedation affects subjective versus objective lameness evaluation is needed to establish whether all cases that require sedation for lameness investigation should be referred to a practice with equipment for objective lameness evaluation.

\section{Methodology Section}

\begin{tabular}{|c|c|}
\hline \multicolumn{2}{|l|}{ Search Strategy } \\
\hline $\begin{array}{r}\text { Databases searched and dates } \\
\text { covered: }\end{array}$ & $\begin{array}{l}\text { CAB Abstracts via Ovid interface 1973-week } 232020 \\
\text { PubMed via NCIB website 1973-June } 2020\end{array}$ \\
\hline Search terms: & $\begin{array}{l}\text { CAB Abstracts: } \\
\text { 1. (horse or horses or equine or equines) } \\
\text { 2. (sedation or sedative or tranquilizer or tranquilisation) } \\
\text { 3. Lameness or gait or blocking } \\
\text { 4. } 1 \text { and } 2 \text { and } 3 \\
\text { PubMed: } \\
\text { (((horse) OR (horses) OR (equine) OR (equines)) AND ((sedation) OR } \\
\text { (sedative) OR (tranquilliser) OR (tranquillisation)) AND ((lameness) } \\
\text { OR (gait))) }\end{array}$ \\
\hline Dates searches performed: & 19 Jun 2020 \\
\hline
\end{tabular}

Exclusion / Inclusion Criteria

Exclusion: Sound horses only without lameness induction, non-English language, review or non-journal articles, not relevant to PICO question

Inclusion: Lame horses or lameness induced, relevant to PICO question, clinical studies 


\begin{tabular}{|l|c|c|c|c|c|c|}
\hline \multicolumn{7}{|l|}{ Search Outcome } \\
\hline \multicolumn{1}{|l|}{ Database } & $\begin{array}{r}\text { Number } \\
\text { of } \\
\text { results }\end{array}$ & $\begin{array}{c}\text { Excluded - } \\
\text { Not English } \\
\text { language }\end{array}$ & $\begin{array}{c}\text { Excluded - } \\
\text { Irrelevant to } \\
\text { PICO question }\end{array}$ & $\begin{array}{c}\text { Excluded - Only } \\
\text { sound horses } \\
\text { included }\end{array}$ & $\begin{array}{c}\text { Excluded - Not } \\
\text { journal article }\end{array}$ & $\begin{array}{c}\text { Total } \\
\text { relevant } \\
\text { papers }\end{array}$ \\
\hline $\begin{array}{l}\text { CAB } \\
\text { Abstracts }\end{array}$ & 47 & 6 & 29 & 6 & 1 & 5 \\
\hline PubMed & 45 & 0 & 36 & 5 & 0 & 4 \\
\hline Total relevant papers when duplicates removed & & & 6 \\
\hline
\end{tabular}

\section{CONFLICT OF INTEREST}

The authors declare no conflict of interest.

\section{REFERENCES}

1. Bassage, L.H. \& Ross, M.W. (2010). Diagnostic Analgesia. In: Diagnosis and Management of Lameness in the Horse: Second Edition. 2nd ed. Saint Louis: W.B. Saunders, 100-135.

DOI: https://doi.org/10.1016/B978-1-4160-6069-7.00010-9

2. Beck Júnior, A.A., De La Côrte, F. D., Brass, K.E., Dau, S.L., Silva, G.B. \& Camillo, M.de A.. (2019). Effect of Xylazine and Butorphanol on Experimental Hind Limb Lameness in Horses. Journal of Equine Veterinary Science. 73, 56-62. DOI: https://doi.org/10.1016/j.jevs.2018.11.007

3. Buchner, H.H., Kübber, P., Zohmann, E. \& Peham, C.H. (1999). Sedation and antisedation as tools in equine lameness examination. Equine Veterinary Journal. 30(S30), 227-230.

DOI: https://doi.org/10.1111/i.2042-3306.1999.tb05223.x

4. De Cozar, M.J. (2019). Can I give alpha-2 agonists for blocking and accurately assess the horse's lameness once blocked? Equine Veterinary Education. 31(2), 111-112.

DOI: https://doi.org/10.1111/eve.12877

5. Moorman, V.J., Bass, L. \& King, M.R. (2019). Evaluation of the effects of commonly used $\alpha_{2}$-adrenergic receptor agonists alone and in combination with butorphanol tartrate on objective measurements of lameness in horses. American Journal of Veterinary Research. 80(9), 868-877. DOI: https://doi.org/10.2460/ajvr.80.9.868

6. Morgan, J.M., Ross, M.W., Levine, D.G., Stefanovski, D., You, Y., Robinson, M.A. \& Davidson, E.J. (2020). Effects of acepromazine and xylazine on subjective and objective assessments of forelimb lameness. Equine Veterinary Journal. 52(4), 593-600. DOI: https://doi.org/10.1111/evj.13225

7. Pilsworth, R. \& Dyson, S. (2015). Where does it hurt? Problems with interpretation of regional and intra-synovial diagnostic analgesia. Equine Veterinary Education, 27(11), 595-603.

DOI: https://doi.org/10.1111/eve.12392

8. Rettig, M.J., Leelamankong, P., Pungsri, P. \& Lischer, C.J. (2015). Effect of sedation on fore- and hindlimb lameness evaluation using body-mounted inertial sensors. Equine Veterinary Journal. 48(5), 603-607. DOI: https://doi.org/10.1111/evj.12463 
9. Ross, M.W. (2010). Movement. In: Diagnosis and Management of Lameness in the Horse: Second Edition, 2nd ed. Saint Louis: W.B. Saunders, 64-80. DOI: https://doi.org/10.1016/B978-1-4160-6069$\underline{7.00007-9}$

10. Seitzinger, A.H., Traub-Dargatz, J.L., Kane, A.J., Kopral, C.A., Morley, P.S., Garber, L.P., Losinger, W.C. \& Hill, G.W. (2000). A comparison of the economic costs of equine lameness, colic and equine protozoal myelocencephalitis (EPM). Proceedings of the 9th International Symposium on Veterinary Epidemiology and Economics.

11. Da Silva Azevedo, M., De La Côrte, F.D., Brass, K.E., Gallio, M., Pozzobon, R., Lopes, M.A.F. \& Lopes, L.F.D. (2015). The Use of Xylazine or Acepromazine Does Not Interfere in the Lameness Evaluation by Inertial Sensors. Journal of Equine Veterinary Science. 35(1), 27-30.

DOI: https://doi.org/10.1016/j.jevs.2014.10.007 


\section{EVIIDEFeE

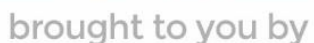 \\ RCVS KNOWLEDGE}

\section{Intellectual Property Rights}

Authors of Knowledge Summaries submitted to RCVS Knowledge for publication will retain copyright in their work, and will be required to grant RCVS Knowledge a non-exclusive license of the rights of copyright in the materials including but not limited to the right to publish, re-

publish, transmit, sell, distribute and otherwise use the materials in all languages and all media throughout the world, and to license or permit others to do so.

\section{Disclaimer}

Knowledge Summaries are a peer-reviewed article type which aims to answer a clinical question based on the best available current evidence. It does not override the responsibility

of the practitioner. Informed decisions should be made by considering such factors as individual clinical expertise and judgement along with patient's circumstances and owners' values. Knowledge Summaries are a resource to help inform and any opinions expressed within the Knowledge Summaries are the author's own and do not necessarily reflect the view of the RCVS Knowledge. Authors are responsible for the accuracy of the content. While the

Editor and Publisher believe that all content herein are in accord with current recommendations and practice at the time of publication, they accept no legal responsibility

for any errors or omissions, and make no warranty, express or implied, with respect to material contained within.

For further information please refer to our Terms of Use.

RCVS Knowledge is the independent charity associated with the Royal College of Veterinary Surgeons (RCVS). Our ambition is to become a global intermediary for evidence based veterinary knowledge by providing access to information

that is of immediate value to practicing veterinary professionals and directly contributes to evidence based clinical decision-making.

\section{https://www.veterinaryevidence.org/}

RCVS Knowledge is a registered Charity No. 230886.

Registered as a Company limited by guarantee in England and Wales No. 598443.

Registered Office: Belgravia House, 62-64 Horseferry Road, London SW1P 2AF

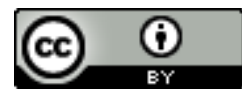

This work is licensed under a Creative Commons Attribution 4.0 International License. 